\title{
High use of private providers for first healthcare seeking by drug-resistant tuberculosis patients: a cross-sectional study in Yangon, Myanmar
}

Sucitro Dwijayana Sidharta ${ }^{1 \dagger}$, Jason Dean-Chen Yin $^{1 \dagger}$, Joanne Su-Yin Yoong ${ }^{1,2}$ and Mishal Sameer Khan ${ }^{3^{*}}$

\begin{abstract}
Background: Drug resistance is a growing challenge to tuberculosis (TB) control worldwide, but particularly salient to countries such as Myanmar, where the health system is fragmented across the public and private sector. A recent systematic review has identified a critical lack of evidence for local policymaking, particularly in relation to drivers of drug-resistance that could be the target of preventative efforts. To address this gap from a health systems perspective, our study investigates the healthcare-seeking behavior and preferences of recently diagnosed patients with drug-resistant tuberculosis (DR-TB), focusing on the use of private versus public healthcare providers.
\end{abstract}

Methods: The study was conducted in ten townships across Yangon with high DR-TB burden. Patients newly-diagnosed with DR-TB by GeneXpert were enrolled, and data on healthcare-seeking behavior and socio-economic characteristics were collected from patient records and interviews. A descriptive analysis of healthcare-seeking behavior was followed by the investigation of relationships between socio-economic factors and type of provider visited upon first feeling unwell, through univariate logistic regressions.

Results: Of 202 participants, only 8\% reported first seeking care at public facilities, while 88\% reported seeking care at private facilities upon first feeling unwell. Participants aged 25-34 (Odds Ratio $=0.33$ [0.12-0.95]) and males (Odds Ratio $=0.39[0.20-0.75]$ ) were less likely to visit a private clinic or hospital than those aged 18-24 and females, respectively. In contrast, participants with higher income were more likely to utilize private providers. Prior to DR-TB diagnosis, $86 \%$ of participants took medications from private providers. After DR-TB diagnosis, only $7 \%$ of participants continued to take medications from private providers.

Conclusion: In urban Myanmar, most patients shifted to being managed exclusively in the public sector after being formally diagnosed with DR-TB. However, since the vast majority of DR-TB patients first visited private providers in the period leading to diagnosis, related issues such as unregulated quality of care, potential delays to diagnosis, and lack of care continuity may greatly influence the emergence of drug-resistance. A greater understanding of the health system and these healthcare-seeking behaviors may simultaneously strengthen TB control programmes and reduce government and out-of-pocket expenditures on the management of DR-TB.

Keywords: Tuberculosis, Myanmar, Drug-resistance, Health systems, Private health sector

\footnotetext{
* Correspondence: mishal.khan@|shtm.ac.uk

${ }^{\dagger}$ Equal contributors

${ }^{3}$ London School of Hygiene and Tropical Medicine, 15-17 Tavistock Place,

London WC1H 9SH, UK

Full list of author information is available at the end of the article
} 


\section{Background}

Although tuberculosis (TB) mortality has fallen by $47 \%$ between 1990 and 2015, TB remains one of the world's deadliest infectious diseases. In 2016 there were still approximately 1.3 million deaths due to TB (among HIVnegative), surpassing an estimated 1.0 million due to HIV / AIDS. Moreover, in recent years, public health experts have become increasingly concerned about the emergence and spread of drug-resistant strains of $\mathrm{TB}$, particularly those that are not controlled by one or both most effective anti-TB drugs, rifampicin and isoniazid (referred to as DR-TB going forward). Growing drugresistance is a major hurdle to global TB control, threatening to stall or even reverse the declines in TB incidence and mortality [1].

Recent WHO figures indicate that $19 \%$ of previouslytreated TB cases and $4.1 \%$ of new TB cases globally were DR-TB. This burden is unequally distributed, both spatially and economically: of the 600,000 DR-TB cases emerging in 2016, 91\% originated in just 30 countries, 22 of which are classified as low or lower-middle income [2]. In most of these countries, government spending on health per capita is relatively low, and out-of-pocket expenditures exceed 15\% of total healthcare costs (well over the suggested benchmark threshold for universal health coverage) [1,3]. These and other systemic barriers - such as high costs of formal diagnosis and treatment; limited accessibility; poor management and infrastructure; and weak regulatory oversight - result in health systems that are already overstrained yet faced with a growing and increasingly complex burden of diseases, creating ideal conditions for the continued rise of drug-resistance [4]. In addition to these macro-level factors, however, the role of patients and their behavior is also critical. Individual beliefs and preferences, as well as household social and financial constraints, can lead to suboptimal risk-taking, healthcare-seeking and compliance-related behaviors, the consequences of which may be further exacerbated by weaknesses in the underlying health system; for instance, poor health literacy coupled with limited access and high prices can lead to delays in diagnosis and treatment [5-7]. Alternatively, lack of patient motivation to comply with treatment, combined with low levels of monitoring will lead to treatment failure and contribute to the emergence of DR-TB $[8,9]$.

Myanmar exemplifies the case of a lower-income country with a high DR-TB burden. The TB incidence rate is 361 per 100,000 population, approximately 2.5 times higher than the global average. DR-TB incidence is approximately 13,000 per year, placing Myanmar among the highest DR-TB burden countries in the world. Overall, $27 \%$ of previously treated TB cases and $5.1 \%$ of new TB cases were estimated to be DR-TB, higher than both the global and regional average [1]. Despite progress towards eliminating infectious diseases per the "Good Health and Wellbeing" portion of the Sustainable Development Goals, Myanmar's health system is still developing. Although international attention and funding has turned towards Myanmar in recent years, low levels of human capital and government spending in healthcare (3. $4 \%$ of general government spending in 2014-2015) [10] continue to constrain access, coverage and service quality. A recent systematic review in Myanmar identified a critical lack of evidence on TB in the local context to inform policy decisions. Specifically, the study highlighted a need for funders and policymakers to have better information about drivers of drug-resistance that could be the target of preventative efforts and health systems strengthening [11]. To address this gap, our present study investigates the healthcare-seeking behavior and preferences of recently diagnosed DR-TB patients.

\section{Methods \\ Study setting}

Myanmar is a lower-middle income country with a population of 53 million as of 2016. It is bordered by China, India, Bangladesh, Thailand, and Laos. Healthcare services in Myanmar are provided by both the private and public sector. The public health sector is overseen by the Ministry of Health and Sports, which manages public services such as those provided by the National TB Programme (NTP). TB control activities are implemented through Yangon's Township Health Departments (THDs), which are the main health facilities providing primary healthcare, including TB diagnosis, case registration, and treatment provision. Private sector providers include hospitals, pharmacies, small clinics, and informal drug sellers and dispensaries, some of which are not formally registered or regularly monitored. Many private healthcare providers or organizations that work in partnership with the government- such as the Myanmar Medical Association (MMA) and Population Service International (PSI) - are regulated and work closely with the NTP to provide standardized treatment [12]. This cross-sectional study was conducted in ten THDs across Yangon, identified by the NTP as having a high DR-TB burden.

\section{Participants}

Our study enrolled all newly-diagnosed adult pulmonary DR-TB patients with confirmed rifampicin resistance based on GeneXpert results at the THDs. Recruitment was conducted over a six-month period from September 2014 to March 2015. The exclusion criteria were: age < 18 years; known pregnancy at time of data collection; residence outside Yangon or in Yangon < 3 months; and extra-pulmonary TB only. 


\section{Data collection}

After verifying eligibility and willingness to participate (through written consent), we retrospectively collected data from DR-TB patients 3 months after diagnosis at THDs. All DR-TB patients had previously been treated for TB. Data were collected by administering a prepiloted, structured questionnaire at the participant's home, collecting data about participant's socio-economic status, symptoms, treatment adherence, healthcareseeking behavior, and treatment support. Questions about healthcare-seeking behavior focused on decisions made when patients had a typical mild or moderate illness (such as a cough) and not specifically for their recent TB symptoms; this allowed data collection on healthcare-seeking before patients may have been aware that they had TB. A local data collector fluent in the native language was trained to administer the questionnaires and assigned to each township.

\section{Data management}

Data collected on paper records was manually checked at the local study site for accuracy by the study supervisor. Data were then entered into Epidata (Version 3.1, The EpiData Association, Odense, Denmark) and checked for quality through blinded double entry and restricting outof-range values. The raw data was then transferred to Stata (version 10, Stat Corporation, College Station, TX) for management and statistical analysis.

\section{Statistical analysis}

We conducted a descriptive analysis, reporting numbers, percentages, and 95\% confidence intervals (of the proportion) for categorical variables summarizing individual and household socio-economic characteristics, as well as key healthcare seeking behaviors. We then investigated the relationship between patients' socio-economic factors and healthcare seeking behavior in terms of visits to a private provider when initially feeling unwell. Specifically, the outcome variable was whether study participants self-reported that they usually visit a private clinic or hospital upon first feeling unwell (with any ailment). Univariate logistic regressions were conducted, and results were stated in terms of odds ratios and 95\% confidence intervals.

\section{Results}

Over the study period, 205 eligible participants with DRTB were diagnosed at the ten THDs. Three refused to participate, resulting in 202 DR-TB participants being included in the final analysis. Demographic and socioeconomic characteristics of the study participants are summarized in Table 1 . Approximately $70 \%$ of the participants are aged between 25 and 54, representing the most active socio-economic group, and the number of
Table 1 Demographic and socio-economic characteristics of DR-TB participants $(N=202)$

\begin{tabular}{|c|c|c|}
\hline Characteristics & $N(\%)$ & $95 \% \mathrm{Cl}$ \\
\hline \multicolumn{3}{|l|}{ Age } \\
\hline $18-24$ & $26(13 \%)$ & $(9-18 \%)$ \\
\hline $25-34$ & $57(28 \%)$ & $(22-35 \%)$ \\
\hline $35-44$ & $43(21 \%)$ & $(16-28 \%)$ \\
\hline $45-54$ & $38(19 \%)$ & $(14-25 \%)$ \\
\hline $55-64$ & $22(11 \%)$ & $(7-16 \%)$ \\
\hline 65> & $16(8 \%)$ & $(5-13 \%)$ \\
\hline Female & $64(32 \%)$ & $(26-39 \%)$ \\
\hline \multicolumn{3}{|l|}{ Ethnic group } \\
\hline Bamar & $169(84 \%)$ & $(78-88 \%)$ \\
\hline Mixed & $6(3 \%)$ & $(1-7 \%)$ \\
\hline Ethnic minority & $27(13 \%)$ & $(9-19 \%)$ \\
\hline \multicolumn{3}{|l|}{ Religion } \\
\hline Buddhist & $185(92 \%)$ & $(87-95 \%)$ \\
\hline Christian & $10(5 \%)$ & (3-9\%) \\
\hline Muslim & $7(4 \%)$ & $(2-7 \%)$ \\
\hline \multicolumn{3}{|l|}{ Marital status } \\
\hline Single never married & $61(30 \%)$ & $(24-37 \%)$ \\
\hline Married / cohabitating & $121(60 \%)$ & $(53-67 \%)$ \\
\hline Divorced / separated / widowed & $20(10 \%)$ & $(7-15 \%)$ \\
\hline \multicolumn{3}{|l|}{ Occupation } \\
\hline Dependent on earnings of a family member & $44(22 \%)$ & $(17-28 \%)$ \\
\hline Daily wage earner & $5(3 \%)$ & $(1-6 \%)$ \\
\hline Self-employed or private employee & $61(30 \%)$ & $(24-37 \%)$ \\
\hline Government employee & $13(6 \%)$ & $(4-11 \%)$ \\
\hline Unemployed & $71(35 \%)$ & $(29-42 \%)$ \\
\hline Retired or other & $8(4 \%)$ & $(2-8 \%)$ \\
\hline \multicolumn{3}{|l|}{ Education level } \\
\hline None or less than primary & $35(17 \%)$ & $(13-23 \%)$ \\
\hline Primary school completed & $54(27 \%)$ & $(21-33 \%)$ \\
\hline Middle school completed & 59 (29\%) & $(23-36 \%)$ \\
\hline High school completed or graduated & $54(27 \%)$ & $(21-33 \%)$ \\
\hline \multicolumn{3}{|l|}{ Household income in kyat (and USD) ${ }^{a}$} \\
\hline 0/100000 (0/91) & $38(19 \%)$ & $(14-25 \%)$ \\
\hline $100,001 / 150000(91 / 136)$ & $38(19 \%)$ & $(14-25 \%)$ \\
\hline $150,001 / 200000(136 / 18)$ & $46(23 \%)$ & $(18-30 \%)$ \\
\hline 200,001/300000 (181/271) & $40(20 \%)$ & $(15-26 \%)$ \\
\hline $300,001 / \max (271 / \max )$ & $33(16 \%)$ & $(12-22 \%)$ \\
\hline Missing & $7(4 \%)$ & $(2-7 \%)$ \\
\hline \multicolumn{3}{|l|}{ Type of dwelling } \\
\hline Permanent & $119(59 \%)$ & $(52-66 \%)$ \\
\hline Informal & $83(41 \%)$ & $(35-48 \%)$ \\
\hline \multicolumn{3}{|l|}{ Patient still alive } \\
\hline Yes & 190 (94\%) & (90-97\%) \\
\hline No & $12(6 \%)$ & (3-10\%) \\
\hline
\end{tabular}


males was roughly double that of females. Although 12 participants died before the interview, they remained in our analysis to avoid bias from removing this subset, and information about healthcare-seeking behavior was collected from their family members.

As expected, most participants are of the Bamar ethnic group (84\%), the dominant ethnic group in Myanmar, and are Buddhist (92\%), the dominant religion in the country. Of the 202 participants, $41 \%$ reported living in informal housing (without official address and usually built of impermanent materials rather than permanent structures).

Table 2 shows the healthcare-seeking behavior of DRTB participants in our study. Only $8 \%$ of study participants reported a preference to seek care at public facilities upon first feeling unwell (with any ailment). Most participants utilized the private sector, with $62 \%$ visiting private clinics and hospitals, and 26\% visiting private pharmacies or drug sellers. A small number (3\%) went to informal drug sellers or traditional healers. For healthcare-seeking behavior in the past 2 years, $72 \%$ reported having seen a private doctor, while use of traditional healers was low (7\%). Before diagnosis of DR-TB was confirmed at a THD, most participants used medications from a private doctor or pharmacy (86\%). Following the diagnosis of DR-TB - at approved government facilities (i.e. NTP or the public sector) - only 34 (17\%) participants still visited private doctors and only 8 out of 34 participants (24\%) took treatment from them. When considering the full range of private providers (not only private doctors, but including pharmacies and traditional healers as well), 15 (7\%) participants reported taking any treatment from these providers following diagnosis.

Table 3 shows the results of univariate logistic regression with the outcome being whether participants reported first seeking care at a private clinic or hospital when they are unwell. Participants aged 25-34 (OR: 0.33 [0.12-0.95]) were significantly less likely to go to a private clinic or hospital than those aged between 18 and 24. Male participants (OR: 0.39 [0.20-0.75]) were also less likely to go to a private clinic or hospital compared to female participants. Participants with greater income had higher odds of visiting private providers, in particular those with incomes above 300,000 Kyat (OR: 5.040 [1.60-15.84]).

\section{Discussion}

Drug-resistant TB is a challenge for resource-constrained settings where healthcare is provided by a range of healthcare providers in the public and private sectors. In countries such as Myanmar, in addition to low government funding [10], fragmented healthcare systems may contribute to the emergence of drug-resistance and reduce
Table 2 Healthcare-seeking behavior of DR-TB participants $(\mathrm{N}=202)$

\begin{tabular}{lll}
\hline Healthcare-seeking behavior & N (\%) & $\begin{array}{l}95 \% \text { Confid } \\
\text { Interval (of } \\
\text { proportion) }\end{array}$ \\
\hline $\begin{array}{l}\text { Type of health care provider visited } \\
\text { Private clinic/hospital }\end{array}$ & $126(62 \%)$ & $(55-69 \%)$ \\
Public clinic/hospital feeling unwell & $16(8 \%)$ & $(5-13 \%)$ \\
Pharmacy (formal) & $53(26 \%)$ & $(21-33 \%)$ \\
Informal drug stores & $3(2 \%)$ & $(1-5 \%)$ \\
Informal non-medical provider/ & $1(1 \%)$ & $(1-4 \%)$ \\
traditional healer & $3(2 \%)$ & $(1-5 \%)$ \\
Nobody & & \\
Visited private doctor in the past 2 years? & \\
No & $56(28 \%)$ & $(22-34 \%)$ \\
Yes & $146(72 \%)$ & $(66-78 \%)$
\end{tabular}

Visited traditional healer in the past 2 years?

$\begin{array}{lll}\text { No } & 188(93 \%) & (89-96 \%) \\ \text { Yes } & 14(7 \%) & (4-11 \%)\end{array}$

Taken any medication from private/pharma before DR-TB diagnosis?

$\begin{array}{lll}\text { No } & 29(14 \%) & (10-20 \%) \\ \text { Yes } & 173(86 \%) & (80-90 \%)\end{array}$

Visited private doctor for DR-TB concerns since diagnosis?

$\begin{array}{lll}\text { No } & 168(83 \%) & (77-88 \%) \\ \text { Yes } & 34(17 \%) & (12-23 \%)\end{array}$

Taken any treatment for DR-TB from private doctor or pharmacy since diagnosis?

$\begin{array}{lll}\text { No } & 194(96 \%) & (92-98 \%) \\ \text { Yes } & 8(4 \%) & (2-8 \%)\end{array}$

Taken any treatment for DR-TB from traditional healer since diagnosis?

$\begin{array}{lll}\text { No } & 194(96 \%) & (92-98 \%) \\ \text { Yes } & 8(4 \%) & (2-8 \%)\end{array}$

Taken any treatment for DR-TB in private sector (private doctor, pharmacy, traditional healer) since diagnosis?
No
$187(93 \%)$
$(88-95 \%)$
Yes
$15(7 \%) \quad(5-12 \%)$

capacity to manage and diagnose drug-resistant cases [13-15]. To our knowledge, ours is the first study to quantitatively evaluate the health-seeking behavior of DRTB patients in Myanmar, focusing on behavior with respect to the use of private healthcare providers.

We found that the vast majority of participants prefer to utilize the private sector and take prescribed medications from private providers when they start feeling unwell. Similar findings are reported in other Southeast and South Asian countries with dominant private sectors $[16,17]$. It is important to highlight the heterogeneity of the provider landscape for allopathic health services in Myanmar and other regional countries; the private 
Table 3 Logistic regression on the type of healthcare provider visited when first time feeling unwell (private clinic/hospital: yes, others: no, $N=202$ )

\begin{tabular}{|c|c|c|c|c|}
\hline Characteristics & Yes & No & $\begin{array}{l}\text { Odds } \\
\text { ratio }\end{array}$ & $\begin{array}{l}95 \% \text { Confidence } \\
\text { interval }\end{array}$ \\
\hline \multicolumn{5}{|l|}{ Age } \\
\hline $18-24$ & 20 & 6 & 1 & 1 \\
\hline $25-34$ & 30 & 27 & $0.33^{*}$ & $(0.12,0.95)$ \\
\hline $35-44$ & 28 & 15 & 0.56 & $(0.19,1.69)$ \\
\hline $45-54$ & 25 & 13 & 0.58 & $(0.19,1.79)$ \\
\hline $55-64$ & 11 & 11 & 0.30 & $(0.09,1.03)$ \\
\hline $65>$ & 12 & 4 & 0.90 & $(0.21,3.85)$ \\
\hline \multicolumn{5}{|l|}{ Sex } \\
\hline Woman & 49 & 15 & 1 & 1 \\
\hline Man & 77 & 61 & $0.39^{* *}$ & $(0.20,0.75)$ \\
\hline \multicolumn{5}{|l|}{ Ethnic group } \\
\hline Bamar & 106 & 63 & 1 & 1 \\
\hline Mixed & 4 & 2 & 1.19 & $(0.21,6.68)$ \\
\hline Ethnic minority & 16 & 11 & 0.86 & $(0.38,1.98)$ \\
\hline \multicolumn{5}{|l|}{ Religion } \\
\hline Buddhist & 115 & 70 & 1 & 1 \\
\hline Christian & 7 & 3 & 1.42 & $(0.36,5.67)$ \\
\hline Muslim & 4 & 3 & 0.81 & $(0.18,3.73)$ \\
\hline \multicolumn{5}{|l|}{ Marital status } \\
\hline Single never married & 42 & 19 & 1 & 1 \\
\hline Married/cohabitating & 73 & 48 & 0.69 & $(0.36,1.32)$ \\
\hline Divorced/separated/widowed & 11 & 9 & 0.55 & $(0.20,1.56)$ \\
\hline \multicolumn{5}{|l|}{ Occupation } \\
\hline $\begin{array}{l}\text { Dependent on earnings of a } \\
\text { family member }\end{array}$ & 36 & 8 & 1 & 1 \\
\hline Daily wage earner & 4 & 1 & 0.89 & $(0.09,9.06)$ \\
\hline $\begin{array}{l}\text { Self-employed or private } \\
\text { employee }\end{array}$ & 35 & 26 & $0.30^{*}$ & $(0.12,0.75)$ \\
\hline Government employee & 7 & 6 & $0.26^{*}$ & $(0.07,0.98)$ \\
\hline Unemployed & 40 & 31 & $0.29^{* *}$ & $(0.12,0.70)$ \\
\hline Retired or other & 4 & 4 & 0.22 & $(0.05,1.08)$ \\
\hline \multicolumn{5}{|l|}{ Education level } \\
\hline None or Less than primary & 20 & 15 & 1 & 1 \\
\hline Primary school completed & 35 & 19 & 1.38 & $(0.58,3.30)$ \\
\hline Middle school completed & 34 & 25 & 1.02 & $(0.44,2.38)$ \\
\hline $\begin{array}{l}\text { High school completed or } \\
\text { graduated }\end{array}$ & 37 & 17 & 1.63 & $(0.68,3.94)$ \\
\hline \multicolumn{5}{|c|}{ Household incomed in kyat (and USD) ${ }^{a}$} \\
\hline 0/100000 (0/91) & 20 & 18 & 1 & 1 \\
\hline $100,001 / 150000(91 / 136)$ & 20 & 18 & 1 & $(0.41,2.46)$ \\
\hline $150,001 / 200000(136 / 181)$ & 27 & 19 & 1.28 & $(0.54,3.04)$ \\
\hline $200,001 / 300000(181 / 271)$ & 25 & 15 & 1.50 & $(0.61,3.70)$ \\
\hline $300,001 / \max (271 / \max )$ & 28 & 5 & $5.04^{* *}$ & $(1.60,15.84)$ \\
\hline
\end{tabular}

Table 3 Logistic regression on the type of healthcare provider visited when first time feeling unwell (private clinic/hospital: yes, others: no, $\mathrm{N}=$ 202) (Continued)

\begin{tabular}{|c|c|c|c|c|}
\hline Characteristics & Yes & No & $\begin{array}{l}\text { Odds } \\
\text { ratio }\end{array}$ & $\begin{array}{l}95 \% \text { Confidence } \\
\text { interval }\end{array}$ \\
\hline Missing & 6 & 1 & 5.40 & $(0.59,49.26)$ \\
\hline \multicolumn{5}{|c|}{ Permanent/informal dwelling } \\
\hline Permanent & 79 & 40 & 1 & 1 \\
\hline Informal & 47 & 36 & 0.66 & $(0.37,1.18)$ \\
\hline
\end{tabular}

healthcare sector includes independently operating, usually unregulated GPs, pharmacies, and hospitals as well as international and local non-government organizations (NGOs) such as Population Services International (PSI). Private GPs also undertake dual practice which means that they are employed in public sector and see private patients outside of office hours as well [18]. Thus, the diverse entities that constitute the private sector add to its complexity. In contrast to the high use of allopathic private providers, we found limited use of traditional or complementary medicine practitioners in Yangon. Finally, regardless of which provider in the private sector participants initially choose, after a diagnosis of DR-TB in the public health sector, we found that the majority switch to using the public sector and do not continue to be treated by private healthcare providers.

A highly-fragmented pathway to care with a large defacto role for the private sector, as found in our study, can facilitate the development of DR-TB. The quality of care received at unregulated private providers is poorly studied or documented through the routine monitoring systems that are applied in the public sector. There is some evidence indicating that diagnosis and treatment in the private sector can deviate from guidelines for appropriate patient management [19] and that poor treatment compliance in the private sector contributes to drug-resistant TB [20-22]. We do not know the length of delay to diagnosis of DR-TB in Myanmar; a long delay to initiating treatment may result in spread of infection and this should be monitored among newly diagnosed DR-TB patients.

From the perspective of patient choice, use of the private or public sector is determined by both push and pull factors. Few studies in Myanmar have looked at the motivations for initially using private as opposed to public healthcare. One study found most people went to a private GP nearby since it was more convenient and was encouraged by former patients who had been cured of the disease. Long waiting times and perceived prolonged risk to exposure in the waiting rooms were also reported as deterrents to the use of the public sector [18]. 
In our study, we found that women were more likely to use private providers, consistent with other research that also found that male TB patients outnumbered females in Yangon's public health sector [23]. Evidence from other settings indicates that women may experience greater stigma from TB or challenges in travelling long distances to reach healthcare, and private providers may be perceived to allow greater patient privacy and be more conveniently located [24-26]. Further research is needed to explain other demographic differences, such as age-related disparities in seeking care from private providers.

The most likely main determinant of switching to the public sector after diagnosis with DR-TB is the high cost of future visits in the private sector, because DR-TB requires expensive medication [27, 28]. A study in Cambodia also found that patients would initially visit private healthcare providers and switch to the public sector once they knew they had TB, because they wanted to access free TB treatment which would not be available in the private sector [29]. Proximity and access to health public facilities did not appear to be a major barrier in our study in an urban setting, with $78 \%$ of the participants able to reach NTPs within $30 \mathrm{~min}$.

A major strength of this study is the collection of data via detailed, face-to-face interviews with all newlydiagnosed DR-TB participants in the studied townships, which has not previously been collected in Myanmar. However, our study is limited in that we only focus on selected townships within Yangon, and so our findings could more representative of urban settings. For example, the finding that few DR-TB patients used traditional healers may differ in rural settings. Costs of seeking care are also missing from our dataset as we did not receive ethical approval to collect this information. Likewise, our study lacks data on delays to diagnosis of DR-TB, as well as the time period between first seeking care in the private healthcare sector and shifting to the public sector. Lastly, there is considerable diversity in private sector providers that we have not investigated. Differences in quality of care, referral practices and costs may differ between registered/regulated private provider and informal or untrained providers.

\section{Conclusions}

As funding increases for infectious disease control in Myanmar, this research provides initial evidence for policy making and resource allocation decisions $[10,11]$. Specifically, our study indicates that private allopathic healthcare providers are the first point of contact when patients are unwell, and they can therefore play a major positive or negative role in healthcare provision in urban settings. Investments that can improve the quality of care, delays to diagnosis, and continuity of care within the private sector, or coordination between the public and private sector, have the potential to impact a large proportion of patients and reduce the growth in drugresistance in Myanmar. The current study adds to the limited evidence on healthcare-seeking behavior among DR-TB patients in Asian settings with pluralistic health systems. Future studies should examine what motivates patients to use the private sector as the first point on contact when ill, and subsequently understand the quality of care for different types of providers within this sector. Longitudinal studies can help elucidate factors associated with timing of diagnosis and treatment uptake, and treatment adherence, which will support the design and funding of effective interventions in the future.

\section{Abbreviations}

AIDS / HIV: Acquired Immunodeficiency Syndrome / Human Immunodeficiency Virus; Cl: Confidence interval; DR-TB: Drug-resistant tuberculosis; GP: General practitioner; MMA: Myanmar Medical Association; NGO: Non-governmental Organization; NTP: National Tuberculosis Programme; OOP: Out of pocket; OR: Odds ratio; PSI: Population Service International; TB: Tuberculosis; THD: Township Health Department; USD: United States Dollars; WHO: World Health Organization

\section{Acknowledgements}

We gratefully acknowledge the support of FHI 360, the participating health facilities in Yangon and the Myanmar National TB Control Programme for facilitating the study data collection.

\section{Funding}

This study was a component of a larger programme of research funded through a grant from the United States Agency for International Development's Control and Prevention - Tuberculosis Project. We gratefully acknowledge the support of FHI 360, the participating health facilities in Yangon and the Myanmar National TB Control Programme for facilitating the study data collection.

\section{Availability of data and materials}

The datasets used and/or analyzed during the current study are available upon request.

\section{Authors' contributions}

SDS wrote the manuscript and performed statistical analysis. JDY wrote the manuscript and aided in the formulation of the conceptual framework for analysis. JY aided the formulation of conceptual framework for analysis. MSK created the conceptual framework for analysis and guided the direction of the analysis and was responsible for overseeing data collection. All authors have read, edited, and approved the manuscript.

\section{Ethics approval and consent to participate}

Ethical clearance was obtained from LSHTM Research Ethics Committee, the FHI 360 Protection of Human Subjects Committee and the Myanmar Ministry of Health and Sports. All individual participants signed consent forms prior to filling out the questionnaire.

\section{Consent for publication}

Not Applicable.

\section{Competing interests}

The authors declare that they have no competing interests.

\section{Publisher's Note}

Springer Nature remains neutral with regard to jurisdictional claims in published maps and institutional affiliations. 


\section{Author details}

'Saw Swee Hock School of Public Health, National University of Singapore, 12 Science Drive 2, \#10-01, Singapore 117549, Singapore. ${ }^{2}$ Center for Economic and Social Research, University of Southern California, 1909 K St NW, Suite 530, Washington, DC 20006-1101, USA. " ${ }^{3}$ London School of Hygiene and Tropical Medicine, 15-17 Tavistock Place, London WC1H 9SH, UK.

Received: 12 September 2017 Accepted: 28 March 2018 Published online: 11 April 2018

\section{References}

1. World Health Organization. Global Tuberculosis Report 2017. 2017. http:// www.who.int/tb/publications/global_report/en/. Accessed on 9 Mar 2018.

2. The World Bank. World development indicators 2017. 2017. https:// openknowledge.worldbank.org/bitstream/handle/10986/26447/WDI-2017web.pdf. Accessed on 9 Mar 2018.

3. Xu K, Evans DB, Carrin G, et al. Protecting households from catastrophic health spending. Health Aff. 2007;26(4):972-83. https://doi.org/10.1377/ hlthaff.26.4.972.

4. Laxminarayan R, Chaudhury RR, Verheij T, et al. Antibiotic resistance in India: drivers and opportunities for action. PLoS Med. 2016;13(3):e1001974. https:// doi.org/10.1371/journal.pmed.1001974.

5. Levy H, Janke A. Health literacy and access to care. J Health Commun. 2016; 21 Suppl 1(Suppl):43-50. https://doi.org/10.1080/10810730.2015.1131776

6. Cai J, Wang $\mathrm{X}, \mathrm{Ma} \mathrm{A}$, et al. Factors associated with patient and provider delays for tuberculosis diagnosis and treatment in Asia: a systematic review and meta-analysis. PLoS One. 2015;10(3):e0120088. https://doi.org/10.1371/ journal.pone.0120088. Zhou D, ed

7. Das D, Dwibedi B. Delay in diagnosis among pulmonary tuberculosis patients of Rayagada District, Odisha, India. Int J Mycobacteriol. 2016;5: S172-3. https://doi.org/10.1016/j.jimyco.2016.09.056.

8. Horter S, Stringer B, Greig J, et al. Where there is hope: a qualitative study examining patients' adherence to multi-drug resistant tuberculosis treatment in Karakalpakstan, Uzbekistan. BMC Infect Dis. 2016;16:362. https:// doi.org/10.1186/s12879-016-1723-8

9. Long $\mathrm{Q}, \mathrm{Qu}$ Y, Lucas H. Drug-resistant tuberculosis control in China: progress and challenges. Infect Dis Poverty. 2016;5:9. https://doi.org/10. 1186/s40249-016-0103-3.

10. Latt NN, Myat Cho S, Htun NMM, et al. Healthcare in Myanmar. Nagoya J Med Sci. 2016;78(2):123-34. https://www.ncbi.nlm.nih.gov/pubmed/ 27303099 . Accessed 24 Apr 2017

11. Khan MS, Schwanke Khilji SU, Saw S, et al. Evidence to inform resource allocation for tuberculosis control in Myanmar: a systematic review based on the SYSRA framework. Health Policy Plan. 2017;32(1):102-9. https://doi. org/10.1093/heapol/czw077.

12. Khan MS, Schwanke Khilji S, Yoong J, et al. Large funding inflows, limited local capacity and emerging disease control priorities: a situational assessment of tuberculosis control in Myanmar. Health Policy Plan. 2017; 32(suppl_2):i22-31. https://doi.org/10.1093/heapol/czx062.

13. Frieden TR, Driver CR, Frieden TR, et al. Tuberculosis control: past 10 years and future progress. Tuberculosis (Edinb). 2003;83(1-3):82-5. https://doi.org/ 10.1016/S1472-9792(02)00060-4.

14. Lönnroth K, Castro KG, Chakaya JM, et al. Tuberculosis control and elimination 2010-50: cure, care, and social development. Lancet. 2010; 375(9728):1814-29. https://doi.org/10.1016/S0140-6736(10)60483-7.

15. Khan MS, Hutchison C, Coker RJ, et al. Preventing emergence of drug resistant tuberculosis in Myanmar's transitioning health system. Health Policy Plan. 2017;32(suppl_2):ii43-50. https://doi.org/10.1093/heapol/czx093.

16. Lönnroth $K$, Thuong LM, Linh PD, et al. Utilization of private and public health-care providers for tuberculosis symptoms in ho chi Minh City, Vietnam. Health Policy Plan. 2001;16(1):47-54. https://www.ncbi.nlm.nih. gov/pubmed/11238430. Accessed 24 Apr 2017.

17. Uplekar M, Pathania V, Raviglione M. Private practitioners and public health: weak links in tuberculosis control. Lancet. 2001;358(9285):912-6. https://doi. org/10.1016/S0140-6736(01)06076-7.

18. Saw S, Manderson L, Bandyopadhyay M, et al. Public and/or private health care: tuberculosis patients' perspectives in Myanmar. Heal Res Policy Syst. 2009;7(1):19. https://doi.org/10.1186/1478-4505-7-19.
19. Watkins RE, Plant AJ. Pathways to treatment for tuberculosis in Bali: patient perspectives. Qual Health Res. 2004;14(5):691-703. https://doi.org/10.1177/ 1049732304263628

20. Mohd Shariff N, Shah SA, Kamaludin F. Predictors of death among drugresistant tuberculosis patients in Kuala Lumpur, Malaysia: a retrospective cohort study from 2009 to 2013. J Glob Antimicrob Resist. 2016;6:102-7. https://doi.org/10.1016/j.jgar.2016.04.005.

21. Mohd Shariff N, Shah SA, Kamaludin F. Previous treatment, sputum-smear nonconversion, and suburban living: the risk factors of multidrug-resistant tuberculosis among Malaysians. Int J Mycobacteriol. 2016;5(1):51-8. https:// doi.org/10.1016/.jijmyco.2015.11.001.

22. Lonnroth K, Thuong LM, Pham DL, et al. Delay and discontinuity - a survey of TB patients' search of a diagnosis in a diversified health care system. Int $J$ Tuberc Lung Dis. 1999;3(11):992-1000. https://www.ncbi.nlm.nih.gov/ pubmed/10587321. Accessed 24 Apr 2017.

23. Khan M, Khine T, Hutchison C, et al. Are current case-finding methods under-diagnosing tuberculosis among women in Myanmar? An analysis of operational data from Yangon and the nationwide prevalence survey. BMC Infect Dis. 2016;16(1):110. https://doi.org/10.1186/s12879-016-1429-y.

24. Balasubramanian R, Garg R, Santha T, et al. Gender disparities in tuberculosis: report from a rural DOTS programme in south India. Int J Tuberc Lung Dis. 2004;8(3):323-32. https://www.ncbi.nlm.nih.gov/pubmed/ 15139471 . Accessed 23 Jan 2018.

25. Yamasaki-Nakagawa M, Ozasa K, Yamada N, et al. Gender difference in delays to diagnosis and health care seeking behaviour in a rural area of Nepal. Int J Tuberc Lung Dis. 2001;5(1):24-31. https://www.ncbi.nlm.nih. gov/pubmed/11263512. Accessed 23 Jan 2018.

26. Khan MS, Sismanidis C, Godfrey-Faussett P. Factors influencing sex differences in numbers of tuberculosis suspects at diagnostic centres in Pakistan. Int J Tuberc Lung Dis. 2012;16(2):172-7. https://doi.org/10.5588/ ijtld.11.0265.

27. Qadeer E, Razia F, Fielding K, et al. Good quality locally produced drugs can be as effective as internationally quality assured drugs in treating multi-drug resistant tuberculosis. PLoS One. 2015;10(4):e0126099. https://doi.org/10. 1371/journal.pone.0126099.

28. Caminero J, Sotgiu G, Zumla A, et al. Best drug treatment for multidrugresistant and extensively drug-resistant tuberculosis. Lancet Infect Dis. 2010; 10(9):621-9. https://doi.org/10.1016/S1473-3099(10)70139-0.

29. Sundaram N, James R, Sreynimol U, et al. A strong TB programme embedded in a developing primary healthcare system is a lose-dose situation: insights from patient and community perspectives in Cambodia. Health Policy Plan. 2017;32(suppl_2):i32-42. https://doi.org/10.1093/heapol/ czX079.

30. Central Bank of Myanmar. Reference Exchange Rate. http://forex.cbm.gov. mm/index.php/fxrate. Accessed on 9 Mar 2018.

\section{Submit your next manuscript to BioMed Central and we will help you at every step:}

- We accept pre-submission inquiries

- Our selector tool helps you to find the most relevant journal

- We provide round the clock customer support

- Convenient online submission

- Thorough peer review

- Inclusion in PubMed and all major indexing services

- Maximum visibility for your research

Submit your manuscript at www.biomedcentral.com/submit 